\title{
Prevalence, causes and magnitude of functional low vision in Sri Lanka: results from a national population based survey
}

\author{
C Gilbert ${ }^{1}$, K Edusuriya ${ }^{2}$, G V S Murthy ${ }^{1,3}$, H B Pant ${ }^{3}$, E Schmidt ${ }^{4}$, S Senanayake ${ }^{2}$, A H Athapattu ${ }^{5}$, \\ M D Priyangani ${ }^{5}$, K R T C Bandara ${ }^{5}$, C Rathnayake ${ }^{5}$, Y G Upali Jayarathne ${ }^{5}$ on behalf the Sri Lanka \\ National Blindness, Visual Impairment and Disability Steering Committee and Survey Team ${ }^{6}$
}

\begin{abstract}
Introduction The following definition of functional low vision is used in surveys to estimate the need for low vision services: corrected visual acuity in the better eye of less than $6 / 18$ down to and including light perception from causes not amenable to treatment. However, such data for Sri Lanka is lacking.

Objectives To determine the prevalence, causes and magnitude of functional low vision in a nationally representative sample of adults aged 40 years and above in Sri Lanka.

Methods Distance visual acuity was measured using a LogMAR $E$ chart. If the acuity was less than $3 / 60$ in either eye, the ability to see hand movements, count fingers or perceive light was assessed. All underwent autorefraction followed by subjective refraction and measurement of best corrected acuity if indicated. Participants with a presenting acuity of $<6 / 12$ in the better eye were examined in details and a cause of visual loss was assigned. Analysis included those who fulfilled the definition of functional low vision.
\end{abstract}

Results Among those examined, 59 participants fulfilled the definition of functional low vision: prevalence $1.02 \%$ (95\% confidence interval 0.77-1.31\%). The commonest causes were complications of cataract surgery $(42.4 \%)$, and posterior segment conditions $(30.5 \%)$ principally and age related macular degeneration (5 cases) and other retinal conditions ( 11 cases). Based on these estimates, 77,600 adults in Sri Lanka may benefit from low vision services.

Conclusions The prevalence of functional low vision is slightly lower than the prevalence of blindness from all causes. Complications of cataract surgery are potentially avoidable causes.
Ceylon Medical Journal 2018; 63 (S2): s40-s44

DOI: http://doi.org/10.4038/cmj.v63i5.8741

\section{Introduction}

The Global Burden of Diseases has recently published data on the prevalence, magnitude and causes of vision loss worldwide for the years 1990 and 2010 [1]. All the analyses used the World Health Organization (WHO) categories of vision loss, which are based on the presenting visual acuity in the better eye. Using these categories, low vision is defined as a combination of mild and moderate visual impairment (i.e., $<6 / 18$ to $3 / 60$ in the better eye) from all causes. However, these categories do not allow the magnitude of individuals who might benefit from low vision services to be estimated, as the majority with low vision as defined above in low and middle-income settings are visually impaired from conditions requiring clinical services for cataract or refractive errors [1]. Recognizing this limitation, in 2002 WHO derived the following definition of "functional low vision" (FLV) for use in surveys to estimate the prevalence of those who might benefit from low vision care. "A person with low vision is one who has impairment of visual functioning even after treatment and/or standard refractive correction, and has a visual acuity of less than $6 / 18$ to perception of light (PL) in the better eye, or a visual field of less than $10^{\circ}$ from the point of fixation, but who uses, or is potentially able to use vision for the planning and/or execution of a task" [2]. The explanatory notes state that this definition should not be the only criterion used for eligibility for low vision services in clinical practice, as those with better

\begin{abstract}
${ }^{1}$ Department of Clinical Research, London School of Hygiene and Tropical Medicine, London, ${ }^{2}$ Department of Ophthalmology, General Hospital, Kandy, Sri Lanka, ${ }^{3}$ Indian Institute of Public Health, Hyderabad, India. ${ }^{4}$ Sightsavers UK, Haywards Heath, West Sussex, UK, ${ }^{5}$ Survey Optometrists, National Blindness, Visual Impairment and Disability Survey, Sri Lanka, ${ }^{6}$ In addition to the above, other members of the Sri Lanka National Blindness, Visual Impairment and Disability Steering Committee and Survey Team: Palitha G Mahipala, Asela Pradeep Abeydeera, Ahamed Jeza, Champa Banagala, KMK Gamage, Saman Senanayake, Sunil Fernando, Lakmini Dissanayake, Nirmi Vitharana, Nimal Edirisinghe, Sunil Settinayake, Kumara RP, Wimalarathne SAHK, Souvik Bandhopadhyaya, Mahesh Dorairaj, Sandeep Bhuttan.
\end{abstract}

Correspondence: GVSM, e-mail: <Gvs.Murthy@lshtm.ac.uk>. Received 19 February 2018 and revised version accepted 23 June 2018. distribution, and reproduction in any medium, provided the original author and source are credited. 
acuity but with low contrast sensitivity, for example, might also benefit. The definition excludes those with preventable or treatable causes of moderate/severe visual impairment or blindness.

Several papers have been published using the WHO definition of FLV, from two large national surveys in Pakistan [3], and Nigeria [4], from RAAB surveys undertaken in 15 countries in Latin America [5], and a local survey in India [6] (Table 1). In these studies the ratio of blindness to FLV ranged from 0.58 to 3.08 , with a third having ratios in the range 0.75-1.25 (i.e., the prevalence of blindness was almost equal to the prevalence of FLV). The purpose of this study is to present findings on the prevalence and cause of FLV in Sir Lanka, using data from a recent national survey of blindness, visual impairment and disability (2013-4), and to compare the findings with other countries.

Sri Lanka, which has a population of 20.4 million, has one of the fastest aging populations, and in 2015, 12.4\% of the population were aged over 60 years [7]. Health care is provided free at the point of delivery in the government sector, but as in many other middle-income countries, Sri Lanka has a shortage of skilled eye health care workers, including optometrists, rehabilitation assistants, counsellors and those able to provide low vision care. In order to provide data for planning eye care services, the Ministry of Health, Government of Sri Lanka, commissioned a national survey of blindness, visual impairment and disability among individuals aged 40 years and above. Data from this survey were used in the analysis.

\section{Methods}

Details of the survey methods have been published in a companion article in this issue. Methods relevant to this analysis are highlighted here.

A nationally representative sample was obtained using probability proportionate to size methods and cluster random sampling. Each district had at least one cluster. The sample size was 6,800 persons aged $\geq 40$ years in 68 clusters across the country. A total of 6,713 individuals were enumerated and invited to participate.

Examination took place in temporary clinics set up in each cluster and two teams worked concurrently after training and a pilot study. Each team had a trained ophthalmologist, two optometrists, a supervisor and a team of interviewers and enumerators. Following enumeration and recruitment, participants were interviewed by a trained interviewer to obtain socio-demographic data and information on their past medical, and medication history. Presenting distance visual acuity (PVA), with spectacle correction if usually worn, was then measured in each eye by an optometrist using a $\log$ MAR tumbling E chart at four meters. Participants had to correctly see at least 4 of the 5 optotypes to pass at any given optotype vision level. If no optotypes could be seen at four meters they were retested at one meter. If no optotypes could be seen at one meter an ophthalmologist assessed participant's ability to count fingers, see hand movements or perceive light in each eye. All participants were interviewed by an ophthalmologist about their ocular history and had a basic slit-lamp examination of anterior and posterior segments. An autorefractor (Topcon 8000) was used to assess refractive errors by an optometrist. If the PVA was $<6 / 12$ in any eyes, autorefractor readings were used as the basis to determine best corrected VA (BCVA), after retinoscopy if required.

The following participants were examined in detail by an ophthalmologist after dilating the pupils using a slit lamp and +90D fundus examination lens: those who could not see $6 / 12$ in one or both eyes, or where basic eye examination revealed an abnormality, or those who had a history of cataract surgery. Fundus images were also captured with a Forus 3 Nethra fundus camera (Forus Health, Bangalore, India) provided the media were clear enough. Individuals with posterior capsule opacity after cataract surgery were excluded from analysis, as capsulotomy could improve VA. Visual field loss was not used in the definition.

\section{Determining the cause of visual loss}

Causes of visual loss were determined by an ophthalmologist for all with a presenting VA of $<6 / 12$ in any eye, following WHO standards for surveys [8]. Firstly, all the disorders contributing to visual loss in each eye, and all relevant underlying causes were recorded. Second, one main cause was selected for each eye. If an eye had more than one cause the following were preferentially selected, if applicable: primary causes (e.g., phthisis following glaucoma surgery, glaucoma was selected), or the disorder contributing most to vision loss. If two conditions contributed equally to visual loss, the most readily treatable was selected. If none were treatable, the most preventable cause was selected. Having established a main cause for each eye, a principal cause for the person was determined, by selecting the cause in the right or left eye, following a similar logic if the causes differed between eyes.

\section{Definitions}

In the analysis, the following definition was used for FLV: BCVA (or PVA in the absence of refractive error) in the better eye of $<6 / 18$ but could perceive light in at least one eye, and the cause was such that no clinical or optical services would improve PVA. Causes were determined using the cause at the person level.

Household level socio-economic status was derived using data on the number of movable assets owned by the family (e.g., television, computer, radio, cycle, motor cycle etc.) and the monetary value of each asset. Monetary values were summed up to give a family asset score, which 
was grouped into quartiles. As the number of participants with FLV was small, analysis combined the upper two and the lower two quartiles. Education was categorized as secondary school level and below or higher than secondary level.

All data were transferred to the Indian Institute of Public Health, Hyderabad, India for cleaning and analysis using Stata 13.0 (Stata Corp, Texas, US).

Prevalence estimates together with $95 \%$ confidence intervals were calculated. Multiple logistic regression analysis was performed to identify risk factors for FLV and to estimate adjusted Odds Ratios (OR). All the analyses took into account the clustering effect (design effect) due to the cluster sampling design adopted for the study. Missing values were excluded from all the analyses. P-values $<0.05$ were considered as being statistically significant.

All participants with a BCVA (or PVA in the absence of a refractive error), in the better eye of less than $6 / 18$ down to and including light perception were identified. All individuals where the main cause was cataract, refractive error or posterior capsule opacity following cataract surgery were removed from the analysis.

For estimating the magnitude of functional low vision among those aged $\geq 40$ years, the estimated prevalence of FLV in the different age categories (40-49 years; 50-59 years; $60-69$ years; $\geq 70$ years) along with the upper and lower bounds of the $95 \%$ confidence interval were applied to the mid-year population of 2014 in each of these age categories. This enabled us to compute the probable number of persons with FLV in each age group, and for the total population aged $\geq 40$ years.

\section{Results}

5,779 of the 6,713 adults enumerated were examined (overall response rate, $86.1 \%$ ) in 68 clusters. Response rates were higher in older age groups and in females and lower among the better educated. Response rates were similar by Province and by urban/rural residence.

A total of 59 participants fulfilled the definition of FLV, giving a prevalence estimate of $1.02 \%$ (95\% confidence interval (95\% CI) $0.77-1.31 \%$ ) (Table 2). The prevalence was significantly higher in the older age group ( $\geq 70$ years) (3.81\%; 95\% CI 2.58- 5.39) vs 0.58\% (95\% CI 0.39- 0.83), $\mathrm{p}<0.001)$, and among those living in poorer households (1.41\%; 95\% CI $1.03-1.88 \%)$ vs $(0.52 \%$; $95 \%$ CI $0.28-0.88 \%$, $\mathrm{p}<0.001)$. In multivariable analyses, these differences remained statistically significant. There were no difference in the prevalence of FLV by sex, ethnicity, education or place of residence.

The commonest cause of FLV was complications following cataract surgery ( 25 cases; $42.4 \%$ ) followed by posterior segment conditions $(18 ; 30.5 \%)$ principally age related macular degeneration ( 5 cases) and other retinal conditions (11 cases).
Based on these findings, we estimate that there are 77,600 adults aged 40 years and above with FLV in Sri Lanka, $47 \%$ of whom are female.

\section{Discussion}

The prevalence estimate of FLV derived for the Sri Lanka survey lies in the range for other countries i.e., between $0.9 \%$ in Mexico and 3.5\% in Nigeria (Table 1). In Nigeria the main causes of FLV were glaucoma (26.5\%), corneal opacity $(21.5 \%)$, macular degeneration $(11 \%)$ and other posterior segment pathology $(9.9 \%)$. The higher prevalence of FLV in Nigeria reflects the higher blindness prevalence (4.2\%). In Nigeria the prevalence of glaucoma is high and access to services is low [9]). Onchocerciasis, trachoma and poor outcomes following couching, a traditional procedure for cataract, are important causes of blindness and FLV, causes which do not occur in Sri Lanka [10]. The prevalence of FLV was also higher in Pakistan than in Sri Lanka with corneal opacity, mainly due to trachoma, being the leading cause [3]. The prevalence of FLV and blindness in studies from India are very similar to that in Sri Lanka (prevalence of FLV and blindness, $1.05 \%$ and $1.3 \%$ respectively) [6].

In Sri Lanka complications of cataract surgery were the commonest cause of FLV, which are potentially avoidable through careful case selection, high quality cataract surgery with implantation of appropriately powered intraocular lenses and follow up to detect and manage complications. Age related macular degeneration, glaucoma and diabetic retinopathy are likely to increase in Sri Lanka as a consequence of aging, and are likely to become more important causes of FLV unless services to manage these chronic eye diseases increase in parallel with the aging population. The estimate of the number of people in Sri Lanka who have the potential to benefit from low vision services is likely to be an under-estimate, as individuals with a visual acuity of $\geq 6 / 18$ but who had visual field loss or poor contrast sensitivity were not included in the prevalence estimate. Overall, many more would need care due to the unmet need of clinical services,

The implications of these findings are that low vision services in Sri Lanka need to respond to the population most affected i.e., the elderly and the less well educated. Levels of literacy in Sri Lanka are very high, and even the older age group are likely to require low vision devices and environmental modification to allow them access to print and to live more independently.

Limitations of this study are that visual fields were not used in the definition as assessing visual fields reliably in a field setting is very challenging. Individuals with FLV were not identified during the survey's fieldwork and so it was not possible to assess whether they had accessed low vision services nor to assess their functional limitations or quality of life. 
Table 1. Summary of data on the prevalence and causes of function low vision from a range of countries

\begin{tabular}{|c|c|c|c|c|c|c|c|c|c|c|}
\hline \multirow[t]{2}{*}{$\begin{array}{l}\text { Region/Country/ } \\
\text { City, State }\end{array}$} & \multirow[t]{2}{*}{$\begin{array}{l}\text { Age } \\
\text { Group }\end{array}$} & \multirow[t]{2}{*}{$\begin{array}{l}\text { Year of } \\
\text { Survey }\end{array}$} & \multicolumn{2}{|c|}{ Prevalence } & \multirow[t]{2}{*}{$\begin{array}{l}\text { Ratio Blind: } \\
\text { FLV }\end{array}$} & \multicolumn{3}{|c|}{ Causes of functional low vision (FLV) } & \multirow[b]{2}{*}{$\%$} & \multirow[b]{2}{*}{ Others } \\
\hline & & & $\begin{array}{l}F L V \\
(\%) \\
\end{array}$ & $\begin{array}{l}\text { Blind } \\
(\%)\end{array}$ & & Commonest & $\%$ & $2^{\text {nd }}$ commonest & & \\
\hline $\begin{array}{l}\text { Sri Lanka } \\
\text { (present study) }\end{array}$ & $\geq 40 \mathrm{yrs}$ & 2014 & 1.0 & 1.7 & 1.70 & $\begin{array}{l}\text { Cataract Surgical } \\
\text { complications }\end{array}$ & 42 & Retinal Diseases & 30 & 28 \\
\hline \multicolumn{11}{|l|}{ South America } \\
\hline Brazil, Campinas & $\geq 50 \mathrm{yrs}$ & 2003 & 2.6 & 1.6 & 0.62 & $\begin{array}{l}\text { Other posterior } \\
\text { segment }\end{array}$ & 43 & $\begin{array}{l}\text { Diabetic } \\
\text { Retinopathy }\end{array}$ & 29 & 28 \\
\hline Cuba, Havana & $\geq 50 \mathrm{yrs}$ & 2005 & 2.6 & 1.9 & 0.73 & Glaucoma & 33 & $\begin{array}{l}\text { Other posterior } \\
\text { segment }\end{array}$ & 33 & 34 \\
\hline Ecuador, national & $\geq 50 \mathrm{y}$ & 2009 & 2.2 & 1.4 & 0.64 & ARMD & 33 & Diabetic retinopathy & 27 & 40 \\
\hline Paraguay, national & $\geq 50 \mathrm{yrs}$ & 2011 & 2.2 & 1.1 & 0.5 & Diabetic Retinopathy & 39 & Glaucoma & 32 & 29 \\
\hline Peru, national & $\geq 50$ yrs & 2011 & 2.2 & 2.1 & 0.95 & ARMD & 55 & Glaucoma & 24 & 21 \\
\hline $\begin{array}{l}\text { Dominican Republic, } \\
\text { national }\end{array}$ & $\geq 50 \mathrm{yrs}$ & 2008 & 2.1 & 2.2 & 1.05 & Glaucoma & 43 & $\begin{array}{l}\text { Other posterior } \\
\text { segment }\end{array}$ & 22 & 35 \\
\hline Chile, Bio Bio & $\geq 50 \mathrm{yrs}$ & 2006 & 2.0 & 1.4 & 0.7 & Diabetic Retinopathy & 30 & $\begin{array}{l}\text { Other posterior } \\
\text { segment }\end{array}$ & 30 & 40 \\
\hline Venezuela, national & $\geq 50$ yrs & 2004 & 1.9 & 2.3 & 1.21 & Glaucoma & 40 & ARMD & 20 & 40 \\
\hline El Salvador, national & $\geq 50 \mathrm{yrs}$ & 2011 & 1.9 & 2.6 & 1.37 & ARMD & 28 & $\begin{array}{l}\text { Other posterior } \\
\text { segment }\end{array}$ & 23 & 49 \\
\hline Honduras, national & $\geq 50 \mathrm{yrs}$ & 2013 & 1.9 & 1.9 & 1.0 & Glaucoma & 38 & ARMD & 20 & 42 \\
\hline Panama, National & $\geq 50 \mathrm{yrs}$ & 2013 & 1.8 & 3.0 & 1.67 & $\begin{array}{l}\text { Other posterior } \\
\text { segment }\end{array}$ & 27 & Glaucoma & 24 & 49 \\
\hline Guatemala, four states & $\geq 50 \mathrm{yrs}$ & 2004 & 1.2 & 3.7 & 3.08 & $\begin{array}{l}\text { Other posterior } \\
\text { segment }\end{array}$ & 84 & Corneal opacity & 11 & 5 \\
\hline Argentina, national & $\geq 50 \mathrm{yrs}$ & 2013 & 1.2 & 0.7 & 0.58 & Diabetic Retinopathy & 33 & ARMD & 17 & 50 \\
\hline Uruguay, national & $\geq 50$ yrs & 2011 & 1.0 & 0.9 & 0.90 & ARMD & 28 & Glaucoma & 25 & 47 \\
\hline $\begin{array}{l}\text { Mexico, Nuevo } \\
\text { Leon State }\end{array}$ & $\geq 50 \mathrm{yrs}$ & 2005 & 0.9 & 1.5 & 1.67 & $\begin{array}{l}\text { Other posterior } \\
\text { segment }\end{array}$ & 46 & Glaucoma & 25 & 29 \\
\hline \multicolumn{11}{|l|}{ Africa } \\
\hline Nigeria & $\geq 40 \mathrm{yrs}$ & 2007 & 3.5 & 4.2 & 1.20 & Glaucoma & 27 & Retinal diseases & 25 & 48 \\
\hline \multicolumn{11}{|l|}{ South Asia } \\
\hline India, Andhra Pradesh & All ages & 2002 & 1.05 & 1.3 & 1.3 & Retinal diseases & 35 & Amblyopia & 26 & 39 \\
\hline Pakistan, National & $\geq 30 \mathrm{yrs}$ & 2002 & 1.7 & 2.7 & 1.6 & Corneal conditions & 34 & Retinal diseases & 30 & 36 \\
\hline
\end{tabular}

Table 2. Risk factors for functional low vision

\begin{tabular}{|c|c|c|c|c|c|c|c|c|c|c|c|}
\hline \multirow[t]{2}{*}{ Parameters } & & \multirow{2}{*}{$\begin{array}{c}\text { Examined } \\
\text { No. }\end{array}$} & \multirow{2}{*}{$\begin{array}{c}\text { No. with } \\
\text { FLV } \\
\text { No. }\end{array}$} & \multicolumn{2}{|c|}{ Prevalence } & \multicolumn{3}{|c|}{ Univariate analysis } & \multicolumn{3}{|c|}{ Multivariate analysis } \\
\hline & & & & $\%$ & $95 \% C I$ & $O R$ & $95 \% C I$ & $P$ value & $O R$ & $95 \% C I$ & $P$ value \\
\hline \multirow[t]{2}{*}{ Age Group } & $50-69 y$ & 4991 & 29 & 0.58 & $0.39-0.83$ & Ref & & & Ref & & \\
\hline & $\geq 70 \mathrm{y}$ & 788 & 30 & 3.81 & $2.58-5.39$ & 6.77 & $4.03-11.38$ & $<0.001$ & 7.03 & $4.12-11.99$ & $<0.001$ \\
\hline \multirow[t]{2}{*}{ Sex } & Male & 2356 & 28 & 1.19 & $0.79-1.71$ & 1.31 & $0.79-2.20$ & 0.293 & 1.38 & $0.82-2.32$ & 0.226 \\
\hline & Female & 3423 & 31 & 0.91 & $0.62-1.28$ & Ref & & & Ref & & \\
\hline \multirow[t]{2}{*}{ Residence } & Urban & 677 & 10 & 1.48 & $0.71-2.7$ & 1.55 & $0.78-3.07$ & 0.209 & 1.73 & $0.85-3.53$ & 0.124 \\
\hline & Rural & 5102 & 49 & 0.96 & $0.71-1.27$ & Ref & & & Ref & & \\
\hline \multirow[t]{4}{*}{ Literacy } & Secondary & & & & & & & & & & \\
\hline & and lower & 5677 & 59 & 1.04 & $0.79-1.34$ & & & & & & \\
\hline & Higher than & 102 & 0 & & & & & & & & \\
\hline & Secondary & & & & & & & & & & \\
\hline \multirow[t]{3}{*}{ Ethnic Group } & Sinhala & 4546 & 44 & 0.97 & $0.7-1.3$ & Ref & & & Ref & & \\
\hline & Tamil & 1053 & 13 & 1.23 & $0.66-2.1$ & 1.28 & $0.69-2.38$ & 0.735 & 1.15 & $0.6-2.23$ & 0.783 \\
\hline & Moors & 180 & 2 & 1.11 & $0.13-3.96$ & 1.15 & $0.28-4.78$ & & 1.001 & $0.22-5.53$ & \\
\hline
\end{tabular}




\section{Table 3. Causes of functional low vision}

\begin{tabular}{lcc}
\hline Causes & $N$ & $\%$ \\
\hline Cataract surgery complications & 25 & 42.4 \\
Retinal conditions excluding age related & 11 & 18.6 \\
macular degeneration, diabetic retinopathy, & & \\
other vasculopathies) & & \\
Amblyopia & 6 & 10.1 \\
Age related macular degeneration & 5 & 8.5 \\
Glaucoma & 3 & 5.1 \\
Corneal opacity & 2 & 3.4 \\
Uncorrected aphakia & 2 & 3.4 \\
Diabetic retinopathy & 1 & 1.7 \\
Vasculopathies & 1 & 1.7 \\
Optic atrophy & 1 & 1.7 \\
Other causes & 2 & 3.4 \\
& 59 & 100 \\
\hline
\end{tabular}

\section{Acknowledgements}

We acknowledge the support from the members of the Steering Committee, the Sri Lanka College of Ophthalmologists, the Vision2020 Secretariat, Ministry of Health and Family Welfare, Sri Lanka, Sightsavers Country Office, Sri Lanka and all the supervisors and field investigators (Madhuni Wijepala, Subhashini Deshappriya, Rasika Damayanthi, Dinusha Sandamali, Ashanti de Silva, Chaturika Madushani, Menaka Rathnayake, Madusha Priyadarshini, Nadeesha Dilhani, Gaya Shanthi) and data entry operators (Sunethra Thennakoon, Kumuduni Sriyalatha) who worked with great diligence in collecting the data from the survey participants. We thank all the survey participants for giving us the time and opportunity to interact with them to collect critical data.

We would like to thank Sightsavers for financial support of the overall study and CBM for financial contributions to the disability component of the survey.

\section{References}

1. Bourne RR, Stevens GA, White RA, et al. Causes of vision loss worldwide, 1990-2010: a systematic analysis. Lancet Glob Health 2013; 1: e339-49.

2. World Health Organization. The Management of Low Vision in Children. Report of a WHO Consultation: Bangkok, July 1992. Geneva, Switzerland: WHO; 1993: PBL/93.27.

3. Shah SP, Minto H, Jadoon MZ, et al. Prevalence and causes of functional low vision and implications for services: the Pakistan National Blindness and Visual Impairment Survey. Invest Ophthalmol Vis Sci. 2008; 49: 887-93.

4. Entekume G, Patel J, Sivasubramaniam S, et al. Prevalence, causes, and risk factors for functional low vision in Nigeria: results from the national survey of blindness and visual impairment. Invest Ophthalmol Vis Sci. 2011; 52: 6714-9.

5. Limburg H, Espinoza R, Lansingh VC, Silva JC. Functional low vision in adults from Latin America: findings from population-based surveys in 15 countries. Rev Panam Salud Publica 2015; 37: 371-8.

6. Dandona R, Dandona L, Srinivas M, Giridhar P, Nutheti R, Rao GN. Planning low vision services in India: a population-based perspective. Ophthalmology 2002; 109: 1871-8.

7. Samaraweera D, Maduwage S. Meeting the current and future health care needs of Sri Lanka's ageing population. WHO South East Asia J Public Health 2016; 5: 96-101.

8. World Health Organization, Geneva, 1988. Coding instructions for the WHO/PBL Eye Examination Record (Version III). WHO/PBL/88.1

9. Abdull MM, Chandler C, Gilbert CE. Glaucoma, "the silent thief of sight": patient perspectives and health seeking behavior in Bauchi, northern Nigeria. BMC Ophthalmology 2016; 16: 44.

10. Abdull MM, Sivasubramaniam S, Murthy GV, et al. Causes of blindness and visual impairment in Nigeria: the Nigeria national blindness and visual impairment survey. Invest Ophthalmol Vis Sci. 2009; 50: 4114-20. 